\title{
Fat embolism showing restriction on diffusion sequence in brain magnetic resonance imaging
}

Restrição na sequência de difusão em imagem de ressonância magnética cerebral de embolia gordurosa

Henry Koiti Sato 1 , Pedro André Kowacs ${ }^{1}$, Paulo Sergio Faro Santos ${ }^{1}$

A 69 year-old female presented with bilateral amaurosis, headache, fever $\left(38^{\circ} \mathrm{C}\right)$ and dyspnea two days after a liposuction and abdominoplasty. A bilateral papilledema was observed in the clinical examination, without other neurological changes. Her ESR was $60 \mathrm{~mm} / \mathrm{h}$ and her platelet count was low $\left(55.000 \mathrm{~mm}^{3}\right)$. Brain MRI revealed restriction of diffusion sequence in the right globus pallidus and both retinas (Figure 1). At spinal tap opening pressure was $16 \mathrm{cmH} 2 \mathrm{O}$. CSF examination was normal. Angio-MRI of the head and neck were also normal. Both transthoracic and transesophagic ecoDoppler examinations of the heart, the latter tailored to exclude left-to-right shunt were normal. The whole investigation of coagulopathy, vasculitis and idiopathic intracranial hypertension were negative. The retinal angiofluoresceinography demonstrated papilledema with venous congestion and retinal hemorrhages and no change in the arterial bed (Figure 2). Patient was submitted to anticoagulation with enoxaparine $1 \mathrm{mg} / \mathrm{kg}$ subcutaneous bid without reversal of amaurosis.

Papilledema leading may be seen in increased intracranial pressure, inflammatory optic neuropathy, infiltrative optic
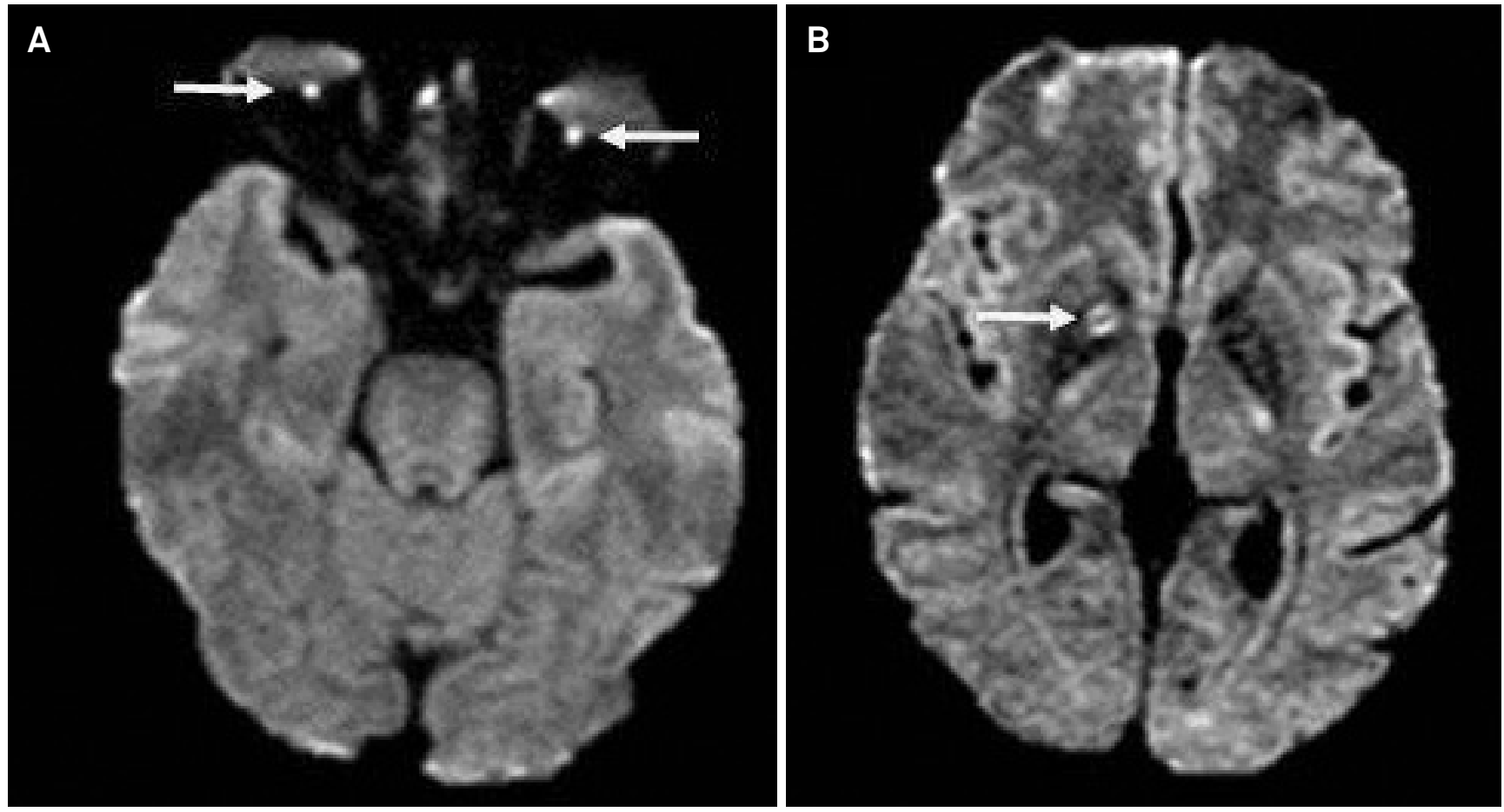

Figure 1. Sign of restriction on the diffusion in both retinas (A) and the globus pallidus to the right (B). 

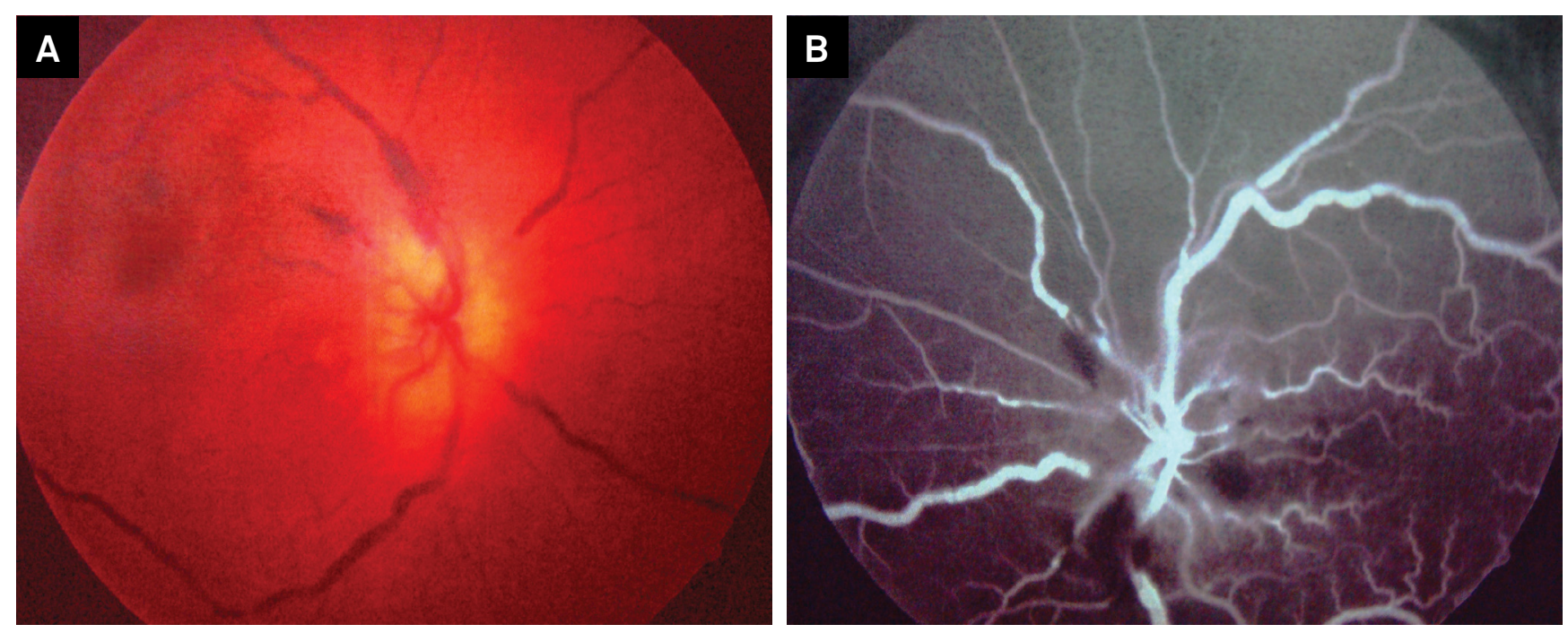

Figure 2. Papilledema with venous congestion (A) and retinal hemorrhage with no change in arterial bed (B).

neuropathy, optic nerve tumours, compressive optic neuropathy, vasculopathies, intra-ocular disease venous obstruction; conditions associated with a massive increase in the protein content of CSF.

There are several mechanisms described for papilledema, such as a stasis of venous and lymphatic drainage secondary to increased pressure in the subarachnoid space, to an inflammatory condition, to venous obstruction by cloths or to mechanic obstruction. Optic nerve ischemia and impaired axoplasmic flow are also mentioned as determinates of a choked disk. In the case described above the sudden onset of the amaurosis, time-locked to the surgical procedure (liposuction) suggests a vascular phenomenon. Liposuction may determine small vessel rupture and adipocyte damage. Fat microfragments are drained by the venous circulation and surpass the pulmonary capillary bed, reaching the arterial system. Criteria for fat embolism were described by Gurd and Wilson (Table) ${ }^{1}$.

We hypothesized that in this case papilledema was caused bilateral cilliary arteries obstruction by fat
Table. Gurd's criteria for fat embolism.

\begin{tabular}{l}
\hline Major criteria \\
\hline Axillary or subconjunctival petechiae \\
Hypoxaemia $\left(\mathrm{PaO}_{2}<60 \mathrm{mmHg} ; \mathrm{FI}_{0} 2=0.4\right)$ \\
Central nervous system depression disproportionate to \\
hypoxaemia \\
Pulmonary oedema \\
\hline Minor criteria \\
\hline Tachycardia $<110 \mathrm{bpm}$ \\
Pyrexia $<38.5^{\circ} \mathrm{C}$ \\
Emboli present in the retina on fundoscopy \\
Fat present in urine \\
A sudden inexplicable drop in haematocrit or platelet values \\
Increasing ESR \\
Fat globules present in the sputum \\
\hline
\end{tabular}

embolism. Similar cases of cerebral fat embolism were described. Surgeons, ophtalmologists, physicians, and neurologist should be aware of this condition².

\section{References}

1. Gurd AR, Wilson RI. The fat embolism syndrome. J Bone Joint Surg Br. 1974;56B(3):408-16.
2. Wang HD, Zheng JH, Deng CL, Liu QY, Yang SL. Fat embolism syndromes following liposuction. Aesthetic Plast Surg. 2008;32(5):731-6. doi:10.1007/s00266-008-9183-1 


\section{Erratum}

Refractory epilepsy in children with brain tumors. The urgency of neurosurgery.

Arq Neuropsiquiatr 2016;74(12):1008-1013. DOI: 10.1590/0004-282X20160157

\section{The authors:}

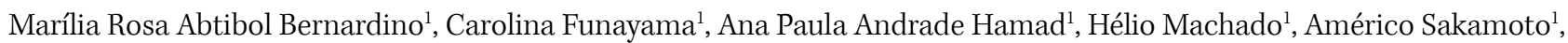
Ursula Thome ${ }^{1}$, Vera Cristina Terra ${ }^{1}$, Antonio Carlos dos Santos ${ }^{1,2,3}$

\section{Should be:}

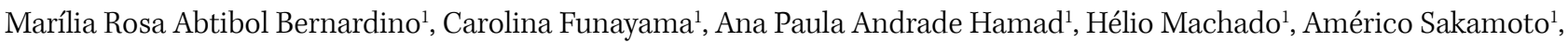
Ursula Thome ${ }^{1}$, Vera CristinaTerra ${ }^{1}$, Antonio Carlos dos Santos ${ }^{1,2,3}$, Luciano Nader Serafani ${ }^{4}$, Nathalia Cunha Calixto ${ }^{2}$, Huria Shalom Monturil de Carvalho Silva ${ }^{4}$

\section{The afiliations:}

${ }^{1}$ Universidade de São Paulo, Faculdade de Medicina de Ribeirão Preto, Departamento de Neurociências e Ciências do Comportamento, Ribeirão Preto SP, Brasil;

${ }^{2}$ Universidade de São Paulo, Faculdade de Medicina de Ribeirão Preto, Departamento de Neuroradiologia, Seção de Ressonância Magnética, Ribeirão Preto SP, Brasil;

${ }^{3}$ Universidade de São Paulo, Faculdade de Medicina de Ribeirão Preto, Hospital das Clínicas, Centro de Ciências das Imagens e Física Médica, Ribeirão Preto SP, Brasil.

\section{Should be:}

${ }^{1}$ Universidade de São Paulo, Faculdade de Medicina de Ribeirão Preto, Departamento de Neurociências e Ciências do Comportamento, Ribeirão Preto SP, Brasil;

${ }^{2}$ Universidade de São Paulo, Faculdade de Medicina de Ribeirão Preto, Departamento de Neuroradiologia, Seção de Ressonância Magnética, Ribeirão Preto SP, Brasil;

${ }^{3}$ Universidade de São Paulo, Faculdade de Medicina de Ribeirão Preto, Hospital das Clínicas, Centro de Ciências das Imagens e Física Médica, Ribeirão Preto SP, Brasil;

${ }^{4}$ Universidade de São Paulo, Faculdade de Medicina de Ribeirão Preto, Departamento de Patologia e Medicina Legal, Ribeirão Preto SP, Brasil.

Aliocha Dostoevski's death during an epileptic seizure.

Arq Neuropsiquiatr 2016; 74 (11): 944-946. DOI: 10.1590/0004-282x20160147

\section{The paragraph:}

However, Anna panicked and called their pediatrician, Dr. A. Tchochin, who lived nearby, picked up the phone immediately. (Page 945)

\section{Should be:}

However, Anna panicked and called their pediatrician, Dr. A. Tchochin, who lived nearby.

\section{Fat embolism showing restriction on diffusion sequence in brain magnetic resonance imaging.}

Arq Neuropsiquiatr 2016;74(7):597-598. DOI: http://dx.doi.org/10.1590/0004-282X20160052

\section{The authors:}

Henry Koiti Sato ${ }^{1}$, Pedro André Kowacs ${ }^{1}$, Josep Dalmau², Paulo Sergio Faro Santos ${ }^{2}$

\section{Should be:}

Henry Koiti Sato ${ }^{1}$, Pedro André Kowacs ${ }^{1}$, Paulo Sergio Faro Santos ${ }^{1}$

The afiliation "'Universitat de Barcelona, Institut D’Investigacions Biomédiques August Pi I Sunyer, Hospital Clínic, Barcelona, Spain." must be ignored. 